OPEN ACCESS

Edited by:

Arjan Te Pas,

Leiden University, Netherlands

Reviewed by:

Guillermo Soza,

University of La Frontera, Chile

Manuela Zlamy,

Innsbruck Medical University, Austria

${ }^{*}$ Correspondence: Nina Dwi Putr ninadwip@gmail.com

Specialty section This article was submitted to Pediatric Infectious Diseases,

a section of the journal

Frontiers in Pediatrics

Received: 30 July 2019 Accepted: 20 March 2020 Published: 15 April 2020

Citation:

Hendarto A, Putri ND, Yunita DR, Efendi M, Prayitno A, Karyanti MR, Satari HI, Hadinegoro SRS and

Chan M (2020) First Pediatric

Outpatient Parenteral Antibiotic Therapy Clinic in Indonesia. Front. Pediatr. 8:156 doi: 10.3389/fped.2020.00156

\section{First Pediatric Outpatient Parenteral Antibiotic Therapy Clinic in Indonesia}

\author{
Aryono Hendarto ${ }^{1}$, Nina Dwi Putri ${ }^{1 *}$, Dita Rizkya Yunita ${ }^{2}$, Mariam Efendi ${ }^{2}$, Ari Prayitno ${ }^{1}$, \\ Mulya Rahma Karyanti ${ }^{1}$, Hindra Irawan Satari ${ }^{1}$, Sri Rezeki S. Hadinegoro ${ }^{1}$ and \\ Monica Chan ${ }^{3}$

\begin{abstract}
1 Department of Child Health, Academic Medical Center, Faculty of Medicine, Cipto Mangunkusumo Hospital, Universitas Indonesia, Jakarta, Indonesia, ${ }^{2}$ Department of Paediatric Nursing, Cipto Mangunkusumo Hospital, Jakarta, Indonesia,

${ }^{3}$ Department of Infectious Diseases, Tan Tock Seng Hospital, Singapore, Singapore
\end{abstract}

Background: Infection remains a major pediatric health problem in Indonesia and usually leads to longer hospitalization due to the need for extended intravenous antibiotic administration. In developed countries, pediatric outpatient parenteral antibiotic therapy (P-OPAT) is well-established and proven to be safe and effective at reducing the length of hospital stay; however, data on low- and middle-income countries such as Indonesia remain limited. This P-OPAT service is new and the first service in Indonesia.

Methods: The medical records of patients attending Indonesia's first P-OPAT clinic between April 2015 and March 2017 were retrospectively investigated.

Results: During the 24-month period, 32 patients received treatment at the P-OPAT clinic, saving a total of 258 bed days. The majority of patients ( $n=16 ; 50 \%)$ were diagnosed with urinary tract infection, followed by cellulitis $(n=4 ; 12.5 \%)$ and osteomyelitis $(n=4 ; 12.5 \%)$. Ceftriaxone was the most commonly used antibiotic ( $n=$ 16; 50\%). All patients used a peripheral intravenous catheter and were sent home with this device. Twelve patients (37.5\%) needed to change IV access more than once. None of the patients used elastomeric infusor device. The median duration of OPAT was 5 days (range 1-27 days). All patients were successfully treated with no recurrence after 30 days. One patient (3.1\%) experienced drug-related complication and another one (3.1\%) was readmitted due to an underlying medical condition. All the patients complied with P-OPAT schedules.

Conclusions: P-OPAT service offers a safe and effective option for the delivery of outpatient intravenous antibiotics in selected patients even in resource-poor settings.

Keywords: ceftriaxone, Indonesia, urinary tract infections, outpatient, antibiotic

\section{INTRODUCTION}

In low- and middle-income countries (LMICs) such as Indonesia, infectious diseases remain the major cause of morbidity in pediatric patients, which commonly leads to hospitalization (1). Severe infections may require prolonged hospital stays due to the need for an extended period of IV antibiotic administration (2). Prolonged hospital stays can harm patients by increasing the risk of nosocomial infections, increasing the family's financial burden, and reducing the psychological well-being, especially in children $(3,4)$. 
One of the measures aimed at decreasing the length of hospital stays, or even avoiding admission altogether, is to facilitate the early discharge by means of outpatient parenteral antibiotic therapy (OPAT) service (5). OPAT involves administration of IV antibiotics in outpatient clinics, home-based settings, or community healthcare facilities on patients who need IV antibiotics and lack a suitable oral antibiotic alternative (6). OPAT has been a well-established treatment option for many adult healthcare facilities in resource-rich countries (7). Although the first OPAT was started in pediatric patients (8). the treatment progress in the pediatric population has not been as fast as in adults (9) OPAT has been proven to be effective, efficient (10), and safe, with low complication rates in both adult and pediatric populations $(11,12)$. On the other hand, in LMICs, OPAT is not yet well-established.

Since 2014, Indonesia had started the National Health Insurance (NHI) policy, progressing to be a universal healthcare service covering all of the citizens of Indonesia. Since this is the first OPAT service in Indonesia, there was still no administrative regulation about this service. There are several challenges in establishing OPAT service in Indonesia. As an alternative to reduce hospital stay, OPAT service is not yet covered in the NHI service. There is also no elastomeric infusors available yet so the antibiotics must be administered in the hospital every day. Our hospital Cipto Mangunkusumo hospital ( $\mathrm{CMH}$ ) also received referred patients from outside of Jakarta. Many of the patients did not have a place to live near the hospital. This resulted in increased travel time or added resources to find a temporary place during the proposed OPAT course.

This study aimed to describe the experience of, and challenges encountered in, developing the first pediatric OPAT (P-OPAT) clinic in Indonesia by examining its outcomes and safety.

\section{METHODS}

\section{Setting}

This was a retrospective study performed in $\mathrm{CMH}$, a tertiary hospital in Jakarta and also a national referral hospital in Indonesia. This hospital is a general hospital with 1,000 beds. There is a need for bed saving days since there is a constant waiting list for pediatric patients in $\mathrm{CMH}$. The P-OPAT clinic in $\mathrm{CMH}$ was established in early 2015. P-OPAT clinic is located at Pediatric Unit of CMH. Our clinic has one bed and two treatment chairs (Figure 1). P-OPAT services are available every day from 8 a.m. to 4 p.m. During weekdays, P-OPAT service runs in POPAT clinic. While, during the weekend, P-OPAT services were delivered in the Emergency Department Treatment Center.

\section{Procedure}

All patients referred to the P-OPAT clinic were from the inpatient ward and emergency department. They were assessed by at least one physician and one nurse. Patients had a clear diagnosis of infection, were clinically stable, and without suitable alternative oral antibiotic. The patient and family were adequately educated about routine care at home, P-OPAT schedule, complications, and emergency access. They were cooperative and confident to be discharged with further follow-up in P-OPAT clinic. Patients
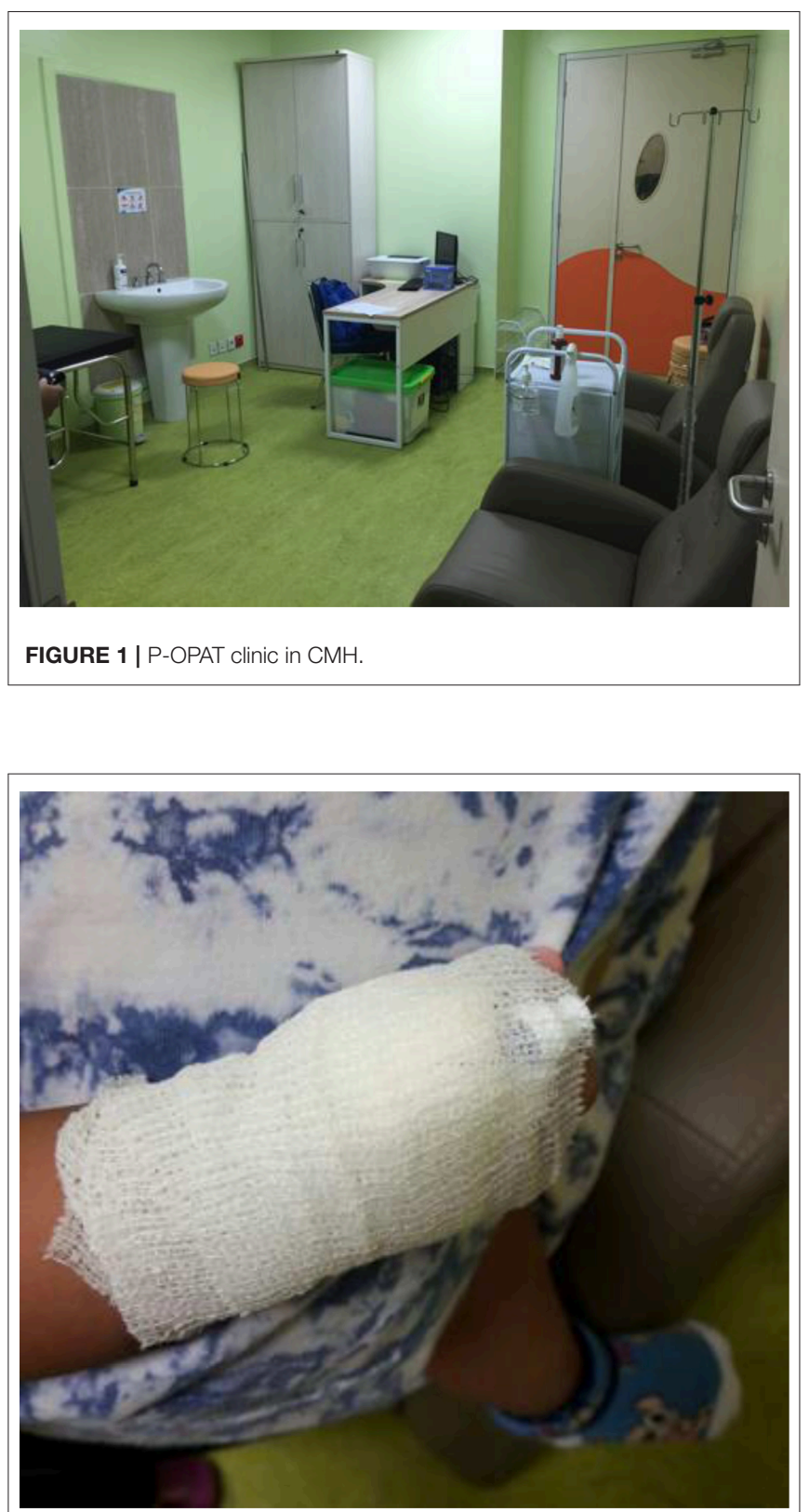

FIGURE 2 | Safety of IV access using special bandage.

and/or their guardians provided informed consent for treatment in P-OPAT clinic. Patients who did not fulfil these criteria were excluded.

To ensure patient safety, all of the first doses of antibiotics were administered at the hospital. A 24-h emergency contact number was provided to assist patients during the P-OPAT service. Peripheral IV access was used in all patients with a neutral valve connector and covered by a bandage to ensure it was safe to bring home (Figure 2). Kits were also provided for every patient, consisting of small dressings, alcohol swabs, and sterile cottons. The P-OPAT guidelines were adopted and adjusted from 
Singapore and the United Kingdom for better implementation in our setting (9).

\section{Data Collection}

This study was conducted through reviewing the medical records of patients who had received treatment in the P-OPAT clinic at CMH between April 2015 and March 2017. Demographic data, clinical characteristics, microbiological results, therapy received, and patient outcomes were obtained at treatment completion and 30 days after. The clinical outcomes consist of treatment rate, bed days saved, frequency of IV access replacement, and recurrence of infection for 30 days after treatment completion. Complications consist of a deterioration of infection, drug- and IV-accessrelated complications, and unscheduled medical visits. Bed days saved was defined as the total number of treatment days in the POPAT clinic. This study was approved by the Faculty of Medicine, University of Indonesia's Research, and Ethics Committee.

\section{RESULTS}

A total of 32 patients received P-OPAT service at CMH (Table 1). The majority ( $n=31 ; 93.8 \%$ ) of patients used national health insurance. Half of the patients lived outside Jakarta City, with a distance of more than $20 \mathrm{~km}$ from CMH. During the 2-year period, this service saved 258 bed days. The most common diagnosis was complicated UTI $(n=16 ; 60 \%)$, followed by cellulitis $(n=4 ; 12.5 \%)$ and osteomyelitis (4; 12.5\%). During the second year period, we also start to take some difficult cases such as brain abscess $(n=1 ; 3.1 \%)$ and native valve endocarditis $(n=1 ; 3.1 \%)$. More than half of the diagnosis were unproven by culture $(n=19 ; 59.4 \%)$. Half of the patients were being treated with ceftriaxone $(n=16 ; 50 \%)$. All patients used peripheral IV access and were discharged home with the peripheral IV access (Table 2).

All patients $(n=32 ; 100 \%)$ were clinically cured at the end of treatment (Table 3). No infections recurred within 30 days of discharge from P-OPAT. Twelve patients (37.5\%) needed to change IV access more than once. One patient $(3.1 \%)$ experienced drug-allergy-related complications during the first dose administered before hospital discharge to the P-OPAT clinic, and another $(n=1 ; 3.1 \%)$ was readmitted due to an underlying medical condition. The compliance rate in this study was $100 \%$.

\section{DISCUSSION}

During the 2-year P-OPAT service in CMH, 258 bed days were saved in the treatment of 32 patients. Admissions were avoided in nine of 32 patients $(28.1 \%$ ) who attended the emergency room. The youngest patient treated at our clinic was 4 months old and completed P-OPAT without any complications. This finding is supported by a report from Utah, which found P-OPAT to be safe even for infants aged under 3 months (13).

Most patients at our P-OPAT clinic are diagnosed with complicated UTIs which were not responded with an oral antibiotic or no option of oral antibiotic. Diagnoses reported in other centers widely varied, but comprised mainly of bone, joint and soft tissue infections, UTIs, bloodstream infections,
TABLE 1 | Baseline demographics of P-OPAT patients.

\begin{tabular}{|c|c|c|}
\hline \multirow[t]{2}{*}{ Characteristics } & \multicolumn{2}{|c|}{ OPAT $(n=32)$} \\
\hline & Total & $\%$ \\
\hline \multicolumn{3}{|l|}{ Sex } \\
\hline Male & 17 & 53.1 \\
\hline Female & 15 & 46.9 \\
\hline \multicolumn{3}{|l|}{ Method of payment } \\
\hline Personal & 2 & 6.3 \\
\hline Indonesian national health insurance & 31 & 93.8 \\
\hline \multicolumn{3}{|l|}{ Home address } \\
\hline Jakarta (location of P-OPAT clinic) & 16 & 50.0 \\
\hline Bekasi (23 km from Jakarta) & 6 & 18.8 \\
\hline Tangerang (25 km from Jakarta) & 2 & 6.2 \\
\hline Other & 8 & 25.0 \\
\hline \multicolumn{3}{|l|}{ Referral } \\
\hline Outpatient clinic & 5 & 15.6 \\
\hline Inpatient ward & 18 & 56.3 \\
\hline Emergency room & 9 & 28.1 \\
\hline \multicolumn{3}{|l|}{ Age by group (years) } \\
\hline$<1$ & 4 & 12.5 \\
\hline $1-5$ & 11 & 34.4 \\
\hline $6-10$ & 7 & 21.9 \\
\hline$>10$ & 10 & 31.2 \\
\hline Age [median (range)] (months) & \multicolumn{2}{|c|}{$80(4-192)$} \\
\hline
\end{tabular}

infections due to cystic fibrosis, and intra-abdominal infections $(5,11,14)$. Two of our patients had endocarditis and brain abscess, diagnoses that usually require stricter criteria (9) for acceptance to P-OPAT. These patients had minimal residual abscess or vegetation, stable clinical condition, and residence in close proximity to the P-OPAT clinic. Studies in adults have shown no differences between the readmission and mortality rates in patients with endocarditis at the OPAT compared to inpatient treatment (15).

The complication rate of P-OPAT in our clinic was low (6.2\%). One patient had an allergic reaction (urticaria) during the administration of the first dose of antibiotic, requiring changes in the type of antibiotics administered. The other patient required scheduled hospitalization for peritoneal dialysis device insertion due to underlying medical illness (chronic kidney disease).

All of our patients were discharged home with peripheral IV access. Ambulatory peripheral inserted central catheters (PICCs) are not yet available in Indonesia. Most centers use PICC and peripheral IV access in P-OPAT, but none have reported whether peripheral IV access was retained upon home discharge as used in our center $(9,11)$. During the 2 -year period, more than $80 \%$ of patients experienced IV replacement of no more than twice, whereas the remainder required additional replacements due to occlusion. Any other complications, such as accidental removal, dislodgment, phlebitis, or infection during the treatment period, were not observed. Ceftriaxone was the most commonly used antibiotic, as reported by many other P-OPAT centers $(5,11$, 13). However, a limitation was that most of the diagnoses were 
TABLE 2 | Clinical characteristics of P-OPAT patients.

\begin{tabular}{|c|c|c|}
\hline \multirow[t]{2}{*}{ Characteristics } & \multicolumn{2}{|c|}{ OPAT $(n=32)$} \\
\hline & Total & $\%$ \\
\hline \multicolumn{3}{|l|}{ Diagnosis } \\
\hline Urinary tract infection & 16 & 50.0 \\
\hline Cellulitis & 4 & 12.5 \\
\hline Osteomyelitis & 4 & 12.5 \\
\hline Native valve endocarditis & 1 & 3.1 \\
\hline Abscess (mandibular and brain) & 2 & 6.3 \\
\hline Fungal infection & 3 & 9.4 \\
\hline Pneumonia & 1 & 3.1 \\
\hline Other infection & 1 & 3.1 \\
\hline \multicolumn{3}{|l|}{ Microorganism } \\
\hline No growth & 19 & 59.4 \\
\hline Escherichia coli & 6 & 18.8 \\
\hline Enterococcus faecalis & 2 & 6.3 \\
\hline Klebsiella pneumonia & 1 & 3.1 \\
\hline K. oxytoca & 1 & 3.1 \\
\hline Staphylococcus aureus & 1 & 3.1 \\
\hline Candida albicans & 1 & 3.1 \\
\hline C. glabrata & 1 & 3.1 \\
\hline \multicolumn{3}{|l|}{ Treatment } \\
\hline Ceftriaxone & 16 & 50.0 \\
\hline Amikacin & 8 & 25.0 \\
\hline Gentamicin & 4 & 12.5 \\
\hline Micafungin & 3 & 9.4 \\
\hline Ganciclovir & 1 & 3.1 \\
\hline Duration of OPAT [median (range)] (days) & \multicolumn{2}{|c|}{$5(1-27)$} \\
\hline Bed days saved & 258 & \\
\hline \multicolumn{3}{|l|}{ Intravenous access type } \\
\hline Central & 0 & 0.0 \\
\hline Peripheral & 32 & 100.0 \\
\hline
\end{tabular}

unproven by culture, making the treatment primarily empirical in nature.

In developing the first P-OPAT in Indonesia, several challenges were faced including the adaptation of the national insurance reimbursement financial model to support the POPAT; obtaining approval from multiple levels of hospital, regional, and national authorities; and promoting awareness and confidence in P-OPAT services among hospital physicians, patients, and patient's family. The extent of P-OPAT services in Indonesia was limited because of the lack of elastomeric infusors to deliver antibiotics that would otherwise require multiple daily dosing which is a standard practice in other OPAT centers $(5,9$, 12). In Indonesia, the elastomeric infusor is still undergoing the national registration process; thus, this limits eligible patients to those requiring once daily single-dose antibiotics. The selection of antibiotics based on dosing convenience and availability should also be balanced against the role of OPAT in supporting the antibiotic stewardship program (16). Although our patients' parents prefer P-OPAT over hospitalization, approximately half of them came from outside the city of Jakarta, creating time inefficiencies that necessitate the consideration of alternatives,
TABLE 3 | Clinical outcomes and complications of P-OPAT service.

\begin{tabular}{|c|c|c|}
\hline \multirow[t]{2}{*}{ Variables } & \multicolumn{2}{|c|}{ Frequency $(n=32)$} \\
\hline & Total & $\%$ \\
\hline \multicolumn{3}{|l|}{ Patient status at completion of OPAT } \\
\hline Clinically cured & 32 & 100 \\
\hline Not cured & 0 & 0 \\
\hline \multicolumn{3}{|l|}{ OPAT monitoring after 30 days } \\
\hline Recurrence of infection & 0 & 0 \\
\hline Continued follow-up for underlying medical condition & 32 & 100 \\
\hline Death & 0 & 0 \\
\hline \multicolumn{3}{|l|}{ Frequency of peripheral IV access replacement } \\
\hline Never & 6 & 18.8 \\
\hline 1 time & 14 & 43.8 \\
\hline 2 times & 5 & 15.6 \\
\hline 3 times & 3 & 9.4 \\
\hline 4 times & 1 & 3.1 \\
\hline$\geq 5$ times & 3 & 9.4 \\
\hline \multicolumn{3}{|l|}{ Complications } \\
\hline No complications & 30 & 93.8 \\
\hline Deterioration of infection & 0 & 0 \\
\hline Admission for the underlying medical condition & 1 & 3.1 \\
\hline Drug-related side effects & 1 & 3.1 \\
\hline IV access-related complications & 0 & 0 \\
\hline Compliance & 32 & 100 \\
\hline
\end{tabular}

such as the introduction of OPAT services in community or district hospitals.

The strength of our study is this P-OPAT clinic is the first POPAT in Indonesia which is one of the LMICs. Besides that, we can show that with limited facilities, we can show that P-OPAT clinic still can run and help to save hospital bed days. In our study, we also showed that using peripheral IV catheter at home is safe for children. But in this study, we also have some limitations which is due to small number of patients and lack of P-OPAT service cost data.

In conclusion, our findings show that P-OPAT is safe and effective for selected pediatric patients and provides an opportunity to introduce additional P-OPAT services, as well as expanding the treatment to adult services in LMICs, such as Indonesia. The use of peripheral IV access can be an option for P-OPAT services in LMICs; however, more robust evidence is needed.

\section{DATA AVAILABILITY STATEMENT}

The raw data supporting the conclusions of this article will be made available by the authors, without undue reservation, to any qualified researcher.

\section{ETHICS STATEMENT}

The studies involving human participants were reviewed and approved by Faculty of Medicine, University of Indonesia Research and Ethics Committee. Written informed consent to 
participate in this study was provided by the participants' legal guardian/next of kin. Written informed consent was obtained from the individual(s), and minor(s)' legal guardian/next of kin, for the publication of any potentially identifiable images or data included in this article.

\section{AUTHOR CONTRIBUTIONS}

$\mathrm{AH}, \mathrm{NP}$, and $\mathrm{SH}$ designed the study. AH, NP, DY, ME, AP, $\mathrm{HS}$, and MK collected and analyzed data. AH, NP, SH, MK, and $\mathrm{MC}$ wrote the manuscript. $\mathrm{HS}, \mathrm{AP}, \mathrm{MC}$, and $\mathrm{SH}$ provided technical support and conceptual advice. AH and NP obtained the research grant. All authors have read and approved the final manuscript.

\section{REFERENCES}

1. Countdown2030.org. Data from: Washington DC: United Nations Children's Fund (UNICEF) and the World Health Organization (WHO); CC BY-NCSA 3.0 IGO. (2017). Available online at: http://countdown2030.org/pdf/ Countdown-2030-complete-with-profiles.pdf (Cited March 4, 2019).

2. Marfil-Garza BA, Belaunzaran-Zamudio PF, Gulias-Herrero A, Zuñiga AC, Caro-Vega Y, Kershenobich-Stalnikowitz D, et al. Risk factors associated with prolonged hospital length-of-stay: 18-year retrospective study of hospitalizations in a tertiary healthcare center in Mexico. PLoS ONE. (2018) 13:e0207203. doi: 10.1371/journal.pone.0207203

3. Schimmel E. The hazards of hospitalization. Qual Saf Health Care. (2003) 12:58-63. doi: $10.1136 /$ qhc. 12.1 .58

4. Gold JM, Hall M, Shah SS, Thomson J, Subramony A, Mahant S, et al. Long length of hospital stay in children with medical complexity. J Hosp Med. (2016) 11:750-6. doi: 10.1002/jhm.2633

5. Patel S, Burzio V, Green H, Rees S, Tebruegge M, Jones C, et al. The impact of pediatric outpatient parenteral antibiotic therapy implementation at a tertiary children's hospital in the United Kingdom. Pediatr Infect Dis J. (2018) 37:e292-7. doi: 10.1097/INF.0000000000002031

6. Seaton RA, Barr DA. Outpatient parenteral antibiotic therapy: Principles and practice. Eur J Intern Med. (2013) 24:617-23. doi: 10.1016/j.ejim.2013.03.014

7. Williams DN, Baker CA, Kind AC, Sannes MR. The history and evolution of outpatient parenteral antibiotic therapy (OPAT). Int J Antimicrob Agents. (2015) 46:307-12. doi: 10.1016/j.ijantimicag.2015.07.001

8. Rucker RW, Harrison GM. Outpatient intravenous medications in the management of cystic fibrosis. Pediatrics. (1974) 54:358-60.

9. Patel S, Abrahamson E, Goldring S, Green H, Wickens H, Laundy M. Good practice recommendations for paediatric outpatient parenteral antibiotic therapy (p-OPAT) in the UK: a consensus statement. J Antimicrob Chemother. (2015) 70:360-73. doi: 10.1093/jac/dku401

10. Psaltikidis EM, Silva END, Bustorff-Silva JM, Moretti ML, Resende MR. Economic evaluation of outpatient parenteral antimicrobial therapy: a systematic review. Expert Rev Pharmacoecon Outcomes Res. (2017) 17:35575. doi: 10.1080/14737167.2017.1360767

\section{FUNDING}

This work was supported by the Indonesian Pediatric Society Research Grant (No: 782/PP IDAI/II/2016).

\section{ACKNOWLEDGMENTS}

The authors would like to thank the patients, their families, and the management of $\mathrm{CMH}$ for supporting the P-OPAT clinic; Wardah Cosmetics' Corporate Social Responsibility program for funding the facility housing of the P-OPAT clinic; and the Asia Pacific Economic Community and Tan Tock Seng Hospital, Singapore, for sponsoring a scholarship aiding the OPAT capacity building. This manuscript was proof read by Nicci S.

11. Hodgson KA, Huynh J, Ibrahim LF, Sacks B, Golshevsky D, Layley $M$, et al. The use, appropriateness and outcomes of outpatient parenteral antimicrobial therapy. Arch Dis Child. (2016) 101:886-93. doi: 10.1136/archdischild-2015-309731

12. Fernandes P, Milliren C, Mahoney-West HM, Schwartz L, Lachenauer CS, Nakamura MM. Safety of outpatient parenteral antimicrobial therapy in children. Pediatr Infect Dis J. (2018) 37:157-63. doi: 10.1097/INF.0000000000001716

13. Krah NM, Olson J, Thorell EA, Esquibel L, Osguthorpe RJ, Pavia AT, et al. Outpatient parenteral antimicrobial therapy in young infants. J Pediatric Infect Dis Soc. (2018) 7:e40-2. doi: 10.1093/jpids/piy002

14. Madigan T, Banerjee R. Characteristics and outcomes of outpatient parenteral antimicrobial therapy at an academic children's hospital. Pediatr Infect Dis J. (2013) 32:346-9. doi: 10.1097/INF.0b013e3182 7ee1c2

15. Kortajarena X, Goenaga MA, Ibarguren M, Goenaga MÁ, Muñoz P, GarcíaLeoni ME, et al. Outpatient parenteral antimicrobial therapy for infective endocarditis in patients over 80 years. Rev Esp Quimioter. (2017) 30: 276-9.

16. Akar A, Singh N, Hyun DY. Appropriateness and safety of outpatient parenteral antimicrobial therapy in children: opportunities for pediatric antimicrobial stewardship. Clin Pediatr. (2014) 53:1000-3. doi: 10.1177/0009922813507999

Conflict of Interest: The authors declare that the research was conducted in the absence of any commercial or financial relationships that could be construed as a potential conflict of interest.

Copyright (c) 2020 Hendarto, Putri, Yunita, Efendi, Prayitno, Karyanti, Satari, Hadinegoro and Chan. This is an open-access article distributed under the terms of the Creative Commons Attribution License (CC BY). The use, distribution or reproduction in other forums is permitted, provided the original author(s) and the copyright owner(s) are credited and that the original publication in this journal is cited, in accordance with accepted academic practice. No use, distribution or reproduction is permitted which does not comply with these terms. 